\title{
Sustainable porous carbons with a superior performance for $\mathrm{CO}_{2}$ capture
}

\author{
Marta Sevilla and Antonio B. Fuertes ${ }^{*}$ \\ Instituto Nacional del Carbón (CSIC), P.O. Box 73, 33080 Oviedo, Spain \\ * Corresponding author (E-mail: abefu@incar.csic.es)
}

\begin{abstract}
Sustainable porous carbons have been prepared by chemical activation of hydrothermally carbonized polysaccharides (starch and cellulose) and biomass (sawdust). These materials were investigated as sorbents for $\mathrm{CO}_{2}$ capture. The activation process was carried out under severe $(\mathrm{KOH} /$ precursor $=4)$ or mild $(\mathrm{KOH} /$ precursor $=2)$ activation conditions at different temperatures in the $600-800^{\circ} \mathrm{C}$ range. Textural characterization of the porous carbons showed that the samples obtained under mild activating conditions exhibit smaller surface areas and pore sizes than those prepared by employing a greater amount of $\mathrm{KOH}$. However, the mildly activated carbons exhibit a good capacity to store $\mathrm{CO}_{2}$, which is mainly due to the presence of a large number of narrow micropores $(<1 \mathrm{~nm})$. A very high $\mathrm{CO}_{2}$ uptake of $4.8 \mathrm{mmol} \cdot \mathrm{g}^{-1}$ $\left(212 \mathrm{mg} \mathrm{CO}{ }_{2} \cdot \mathrm{g}^{-1}\right)$ was registered at room temperature $\left(25^{\circ} \mathrm{C}\right)$ for a carbon activated at $600^{\circ} \mathrm{C}$ using $\mathrm{KOH} /$ precursor=2. To the best of our knowledge, this result constitutes the largest ever recorded $\mathrm{CO}_{2}$ uptake at room temperature for any activated carbon. Furthermore, we observed that these porous carbons have fast $\mathrm{CO}_{2}$ adsorption rates, a good selectivity for $\mathrm{CO}_{2}-\mathrm{N}_{2}$ separation and they can be easily regenerated.
\end{abstract}




\section{Broader context}

The mitigation of carbon dioxide emissions is attracting widespread attention due to the fact that this gas is the main anthropogenic contributor to climate change. Among the possible strategies for $\mathrm{CO}_{2}$ abatement, that of capture and storage has attracted keen interest. In this regard, the use of solid sorbents to capture $\mathrm{CO}_{2}$ by means of pressure, temperature or vacuum swing adsorption systems constitutes a promising alternative. To accomplish this objective the sorbents need to satisfy important conditions: i) low-cost and high availability, ii) a large $\mathrm{CO}_{2}$ uptake, iii) a high sorption rate, iv) a good selectivity between $\mathrm{CO}_{2}$ and other competing gases (i. e. $\mathrm{N}_{2}$ ) and v) an easy regenerability. However, the development of a solid sorbent that satisfies all these conditions has so far proved to be complex. Here we present a novel route for the preparation of carbon-based porous sorbents of $\mathrm{CO}_{2}$ from a low-cost sustainable biomass product (sawdust). The results obtained show that these carbon sorbents exhibit very large $\mathrm{CO}_{2}$ adsorption uptakes of up to $4.8 \mathrm{mmol} \cdot \mathrm{g}^{-1}\left(212 \mathrm{mg} \mathrm{CO} \cdot \mathrm{g}^{-1}\right)$ at room temperature $\left(25^{\circ} \mathrm{C}\right)$, a value that far exceeds those reported in the literature for activated carbons. Furthermore, these carbon sorbents exhibit high sorption rates, a good $\mathrm{CO}_{2}-\mathrm{N}_{2}$ selectivity and they can be easily regenerated. 


\section{Introduction}

The control of anthropogenic $\mathrm{CO}_{2}$ emissions is a crucial matter in view of the significant role that this gas plays in global climate change. In recent years, great efforts have been directed towards the development of new technologies for $\mathrm{CO}_{2}$ capture and its storage, the improvement of energy efficiency and the generation of energy from non-fuel sources. For the capture of $\mathrm{CO}_{2}$, the most popular technology is the absorption process using alkanolamine solvents. ${ }^{1}$ However, this process presents several disadvantages, such as a high energy consumption, solvent regeneration, the corrosion of the equipment and toxicity. ${ }^{2} \mathrm{~A}$ promising alternative technology to the liquid-phase absorption process is to use porous solids as sorbents for capturing $\mathrm{CO}_{2}$ by means of pressure, temperature or vacuum swing adsorption systems..$^{3-8}$ To this end, numerous porous solids including zeolites, metal-organic frameworks (MOFs), porous carbons or organic-inorganic hybrid sorbents have been investigated. ${ }^{9-11}$ Hybrid sorbents require costly and multi-step fabrication procedures that involve the impregnation or grafting of porous solids (i. e. silica or carbons) with different types of amines. ${ }^{12-16}$ Furthermore, these materials require high regeneration temperatures and undergo a substantial loss of adsorption capacity after several cycles. Of the sorbents mentioned so far, porous carbons have several important advantages in terms of cost, availability, large surface area, an easy-to-design pore structure, hydrophobicity and low energy requirements for regeneration. However, most activated carbons exhibit $\mathrm{CO}_{2}$ uptakes below $~ 3-4 \mathrm{mmol} \mathrm{CO}_{2} \cdot \mathrm{g}^{-1}$ sorbent $\left(25^{\circ} \mathrm{C}, 1 \mathrm{~atm}\right)$, the value reported as representing the minimum working capacity necessary to compete with the liquid-phase amine systems. ${ }^{17}$ In order to improve the $\mathrm{CO}_{2}$-adsorption capacity of porous carbons, a large amount of research effort has been directed towards the creation of superficial basic sites via the incorporation of nitrogen groups into the carbon framework. ${ }^{18-20}$ However, until now this strategy has only produced moderate enhancements of $\mathrm{CO}_{2}$ uptakes. Thus, Hao et al. recently reported a maximum $\mathrm{CO}_{2}$ adsorption capacity of $3.13 \mathrm{mmol} \cdot \mathrm{g}^{-1}\left(25^{\circ} \mathrm{C}, 1 \mathrm{~atm}\right)$ for $\mathrm{N}$-enriched carbon 
samples ( $\mathrm{N}$ content up to $1.9 \mathrm{wt} \%) .{ }^{20}$ Wahby et al. showed that carbons with high surface areas produced by the chemical activation of petroleum pitch exhibit an excellent performance for $\mathrm{CO}_{2}$ adsorption $\left(4.7 \mathrm{mmol} \cdot \mathrm{g}^{-1}\right.$ at $25^{\circ} \mathrm{C}$ and $\left.1 \mathrm{~atm}\right){ }^{21}$ This result clearly demonstrates that porous carbons with a suitable pore structure are excellent sorbents for $\mathrm{CO}_{2}$ capture.

Taking into account the potential scale involved in the production of porous carbons for $\mathrm{CO}_{2}$ capture, the use of renewable sources for fabricating these materials would seem highly desirable. This could be achieved by employing biomass or biomass-derived products as precursors for the production of carbon sorbents for $\mathrm{CO}_{2}$ capture. Unfortunately, to date this alternative has hardly been explored to this end. In this paper we present a novel route for the preparation of carbon-based $\mathrm{CO}_{2}$ sorbents from sustainable biomass products. The results obtained show that these carbon materials exhibit large $\mathrm{CO}_{2}$ adsorption uptakes, which are far superior to those reported in the literature for activated carbons. The present work focuses above all on the relationship between the porous characteristics of the carbon sorbents and their capacity for $\mathrm{CO}_{2}$ adsorption. Interestingly, the porosity of these carbons can be easily designed by simply modifying the operational conditions (i. e. activation temperature and the amount of activating agent). It is worth mentioning that, if the pore characteristics of these carbons are properly designed, their capacity for $\mathrm{CO}_{2}$ adsorption can be optimized and fully exploited.

\section{Experimental}

\section{Synthesis of porous carbons}

Carbonaceous materials were prepared by hydrothermal carbonization of the following substances: potato starch (Sigma-Aldrich), cellulose (Aldrich) and eucalyptus sawdust. Briefly, an aqueous dispersion of the raw material (concentration: $320 \mathrm{~g} \mathrm{~L}^{-1}$ ) was placed in a stainless steel autoclave, heated up to $250^{\circ} \mathrm{C}$ and maintained at this temperature for $2 \mathrm{~h}$. The 
resulting carbonaceous solid, denoted as hydrochar $(\mathrm{HC})$, was recovered by filtration, washed with distilled water and dried.

The hydrochar materials were chemically activated using potassium hydroxide (Sigma-Aldrich). Briefly, a $\mathrm{HC}$ sample was thoroughly mixed with $\mathrm{KOH}$ at the desired weight ratio $(\mathrm{KOH} / \mathrm{HC}=2$ or 4$)$, after which the mixture was heat treated up to the target temperature (heating rate: $3^{\circ} \mathrm{C} \mathrm{min}^{-1}$ ) under a nitrogen gas flow and held at this temperature for $1 \mathrm{~h}$. The samples were then thoroughly washed several times with $10 \mathrm{wt} \% \mathrm{HCl}$ to remove any inorganic salts, washed with distilled water until neutral $\mathrm{pH}$ and finally dried in an oven at $120^{\circ} \mathrm{C}$ for $3 \mathrm{~h}$. The activated carbons thus synthesized were denoted as $\mathrm{A} X-X-\mathrm{z}$, where $X$ refers to the raw material (A: starch, $\mathrm{C}$ : cellulose and $\mathrm{S}$ : sawdust), $y$ the $\mathrm{KOH} / \mathrm{HC}$ weight ratio and $z$ the activation temperature $\left(\right.$ in $\left.{ }^{\circ} \mathrm{C}\right)$.

\section{Characterization of materials}

The morphology of the samples was examined by Scanning Electron Microscopy (SEM) using a Zeiss DSM 942 microscope. Transmission electron micrographs (TEM) were taken on a JEOL (JEM-2000 FX) apparatus operating at $200 \mathrm{kV}$. The nitrogen sorption isotherms and textural properties of the carbons were determined at $-196^{\circ} \mathrm{C}$ using a conventional volumetric technique (Micromeritics ASAP 2020). The surface area was calculated by the BET method from the adsorption data obtained in the relative pressure $\left(\mathrm{p} / \mathrm{p}_{\mathrm{o}}\right)$ range of 0.04 to 0.2. The total pore volume was determined from the amount of nitrogen adsorbed at $\mathrm{p} / \mathrm{p}_{\mathrm{o}}=0.99$. The pore size distribution (PSD) was calculated via a Non Local Density Functional Theory (NLDFT) method using nitrogen adsorption data and assuming a slit pore model. The micropore surface area and total micropore volume (pore size $<2 \mathrm{~nm}$ ) were obtained via a t-plot analysis. The volume of the narrow micropores $(<0.7 \mathrm{~mm})$ was determined by the applying the Dubinin-Radushkevitch (D-R) equation to the $\mathrm{CO}_{2}$ adsorption data at $0^{\circ} \mathrm{C}^{22}$ 


\section{$\mathrm{CO}_{2}$ adsorption measurements}

The adsorption of $\mathrm{CO}_{2}$ was measured using a Nova 4200e (Quantachrome) static volumetric analyzer. Prior to the adsorption analysis, the sample (around 50-100 $\mathrm{mg}$ ) was degassed at $150^{\circ} \mathrm{C}$ for several hours. The $\mathrm{CO}_{2}$ adsorption experiments were performed at three temperatures: $0^{\circ} \mathrm{C}, 25^{\circ} \mathrm{C}$ and $50^{\circ} \mathrm{C}$.

The adsorption kinetics of the $\mathrm{CO}_{2}$ and $\mathrm{N}_{2}$, and adsorption-desorption cycles were measured in a thermogravimetric analyser (C. I. Electronics). Both sets of experiments were performed at $25^{\circ} \mathrm{C}$ and the temperature was controlled by means of a circulating bath (Haake K15). For the kinetic analysis, the sample $(\sim 10 \mathrm{mg})$ was degassed under a He stream at $200^{\circ} \mathrm{C}$ for 1 hour. The gas was then switched from $\mathrm{He}$ to $\mathrm{CO}_{2}$ or $\mathrm{N}_{2}\left(100 \mathrm{~mL} \cdot \mathrm{min}^{-1}\right)$ and the weight variation with time was recorded. In the case of the adsorption-desorption cycles, the sample $(\sim 30 \mathrm{mg})$ was degassed under a stream of $\mathrm{He}$ at a temperature of $200^{\circ} \mathrm{C}$ before the cyclic experiments. During the adsorption, the carbon sample was exposed to a stream of pure $\mathrm{CO}_{2}\left(100 \mathrm{~mL} \cdot \mathrm{min}^{-1}\right)$. Once the sample was saturated, the gas was switched from $\mathrm{CO}_{2}$ to He $\left(100 \mathrm{~mL} \cdot \mathrm{min}^{-1}\right)$ and the carbon dioxide was desorbed. This adsorption-desorption cycle was repeated several times.

\section{Results and Discussion}

\section{Structural properties of the porous carbons}

The hydrochar samples obtained by subjecting the raw materials (starch, cellulose or sawdust) to hydrothermal carbonization have a brown colour consistent with a partially carbonized product. Inspection of this material by means of scanning electron microscopy (SEM) reveals interesting changes in relation to the raw materials. The eucalyptus sawdust shows a cellular structure that is typical of lignocellulosic materials (Figures 1a). On the other hand, starch and cellulose are formed by particles with an irregular morphology (images not 
shown). The SEM images of the hydrochar samples reveal the presence of a large fraction of carbonaceous microspheres generated during hydrothermal carbonization due to the decomposition of saccharides (see Figs. 1b, 1c and 1d). ${ }^{23,24}$ In the case of the sawdust-based hydrochar, these microspheres are mixed with irregular structures derived from the nonsaccharide components of wood (i. e. lignin) (Figure 1d). Regardless of the hydrochar precursor, all the activated carbons exhibit a similar morphology that is characterized by irregular shaped particles with large conchoidal cavities and smooth surfaces (Figure 1e). This result shows that a drastic morphological change has occurred during the activation process and that the activated carbons retain no memory of the structure of the parent hydrochar. The TEM image of the activated carbon AS-4-700 evidences that the porosity is made up of randomly oriented uniform micropores (Figure 1f).

The textural properties of the activated carbons were analysed by means of nitrogen physisorption. Figure 2 a presents a comparison of the $\mathrm{N}_{2}$ sorption isotherms and pore size distributions (PSDs) of the activated carbons resulting from the chemical activation $\left(700^{\circ} \mathrm{C}\right.$, $\mathrm{KOH} / \mathrm{HC}=4)$ of the hydrochar samples taken from the starch, cellulose and sawdust. Independently of the nature of the precursor, the sorption isotherms have a similar shape and the PSDs indicate that the porosity of these carbons is made up of micropores with a size of around $1.2 \mathrm{~nm}$. As indicated in Table 1, these porous carbons have comparable BET surface areas in the $2200-2400 \mathrm{~m}^{2} \cdot \mathrm{g}^{-1}$ range and pore volumes of $\sim 1.1 \mathrm{~cm}^{3} \cdot \mathrm{g}^{-1}$. Interestingly, the porous carbon derived from a complex, low-cost and highly available material such as sawdust exhibits a similar pore development to the active carbons obtained from more expensive polysaccharides (cellulose and starch). This result anticipates that the porous carbons derived from sawdust, starch and cellulose will exhibit similar $\mathrm{CO}_{2}$ adsorption capacities. This hypothesis was confirmed by means of $\mathrm{CO}_{2}$ adsorption experiments (vide infra). Consequently, taking into account these results, the sawdust-based hydrochar was 
chosen as starting material as it combines low cost and high availability with good $\mathrm{CO}_{2}$ capture capacity.

Figure 3 shows the $\mathrm{N}_{2}$ sorption isotherms and PSDs of the samples prepared at different activation temperatures and for two amounts of $\mathrm{KOH}$, i. e. $\mathrm{KOH} / \mathrm{HC}=4$ (Figs. $3 \mathrm{a}$ and $3 \mathrm{~b}$ ) and $\mathrm{KOH} / \mathrm{HC}=2$ (Figs. $3 \mathrm{c}$ and $3 \mathrm{~d}$ ). The textural characteristics of these materials are listed in Table 1. The porous carbons obtained for $\mathrm{KOH} / \mathrm{HC}=4$ exhibit BET surface areas $>2000 \mathrm{~m}^{2} \cdot \mathrm{g}^{-}$ ${ }^{1}$ (up to $2850 \mathrm{~m}^{2} \cdot \mathrm{g}^{-1}$ for the AS-4-800) and pore volumes $>1 \mathrm{~cm}^{3} \cdot \mathrm{g}^{-1}$. More interestingly, the porosity of these activated carbons is made up of pores in the micropore-mesopore range (sizes between $1 \mathrm{~nm}$ and $3 \mathrm{~nm}$ ) as evidenced by the PSDs shown in Figure $3 \mathrm{~b}$ and Table 1. By contrast, the samples synthesised employing $\mathrm{KOH} / \mathrm{HC}=2$ and temperatures in the 600$700^{\circ} \mathrm{C}$ range, exhibit a moderate degree of activation, as evidenced by the relatively low values obtained for the BET surface areas $\left(\sim 1300 \mathrm{~m}^{2} \cdot \mathrm{g}^{-1}\right)$ and pore volumes $\left(\sim 0.6 \mathrm{~cm}^{3} \cdot \mathrm{g}^{-1}\right)$ (see Table 1). Unlike the samples obtained for $\mathrm{KOH} / \mathrm{HC}=4$, the porosity of the carbons prepared under milder conditions $(\mathrm{KOH} / \mathrm{HC}=2)$ is made up of narrower micropores with sizes $<1 \mathrm{~nm}$ (maxima $\sim 0.8-0.9 \mathrm{~nm}$ ), as illustrated in Figure $3 \mathrm{~d}$ and Table 1 . At a high activation temperature $\left(800^{\circ} \mathrm{C}\right.$ and $\left.\mathrm{KOH} / \mathrm{HC}=2\right)$, there is an enlargement of the size of the micropore (see Fig. 3d) and the activated carbon AS-2-800 exhibits pore characteristics that are comparable to those of the materials synthesised at $\mathrm{KOH} / \mathrm{HC}=4$ (see Table 1).

The narrow microporosity $(<0.7 \mathrm{~nm})$ present in these samples was analyzed by applying the Dubinin-Radushkevitch equation to the $\mathrm{CO}_{2}$ adsorption data obtained at $0{ }^{\circ} \mathrm{C}$. The pore volume $\left(\mathrm{V}_{\mathrm{o}}\right)$ corresponding to these micropores is listed in Table 1. It can be seen that for the highly activated carbons $(\mathrm{KOH} / \mathrm{HC}=4)$, these narrow micropores comprise around $30-40 \%$ of the micropore volume $\left(\mathrm{V}_{\text {micro }}\right)$. In contrast, for the porous carbons obtained under milder conditions $\left(\mathrm{KOH} / \mathrm{HC}=2\right.$ and temperatures in the $600-700^{\circ} \mathrm{C}$ range), the porosity is mostly made up of narrow micropores ( $>80 \%$ of the micropore volume). These results show that 
the fraction of narrow microporosity depends heavily on the degree of activation to which the carbons are subjected. We observed that this parameter has an important role in determining the $\mathrm{CO}_{2}$ adsorption properties of porous carbons.

\section{$\mathrm{CO}_{2}$ capture capacity}

The $\mathrm{CO}_{2}$ adsorption capacities of porous carbons were investigated at three representative temperatures $\left(0{ }^{\circ} \mathrm{C}, 25{ }^{\circ} \mathrm{C}\right.$ and $\left.50{ }^{\circ} \mathrm{C}\right)$. A comparative analysis of the $\mathrm{CO}_{2}$ adsorption isotherms (measured at $0^{\circ} \mathrm{C}$ ) between the sustainable porous carbons and the commercial activated carbon (M-30) is presented in Figure 4. It can be seen that the $\mathrm{CO}_{2}$ capture capacities of the three sustainable carbons are quite substantial and similar (about 5.5-5.8 mmol $\left.\mathrm{CO}_{2} \cdot \mathrm{g}^{-1}, 243-256 \mathrm{mg} \mathrm{CO} \cdot \mathrm{g}^{-1}\right)$. This result is coherent with the fact that the pore characteristics of these materials are analogous (see Table 1).

Table 2 summarizes the $\mathrm{CO}_{2}$ capture capacities of the porous carbons. The highly activated sawdust-based carbons prepared by employing $\mathrm{KOH} / \mathrm{HC}=4$ exhibit similar $\mathrm{CO}_{2}$ uptakes irrespective of the activation temperature. Indeed, the capture capacities at adsorption temperatures of $0{ }^{\circ} \mathrm{C}$ and $25{ }^{\circ} \mathrm{C}$ are in the 5.2-5.8 $\mathrm{mmol} \mathrm{CO}_{2} \cdot \mathrm{g}^{-1}\left(230-256 \mathrm{mg} \mathrm{CO} \mathrm{CO}^{-1}\right)$ and 2.9-3.5 $\mathrm{mmol} \mathrm{CO} \mathrm{CO}_{2} \cdot \mathrm{g}^{-1}\left(128-155 \mathrm{mg} \mathrm{CO} \cdot \mathrm{g}^{-1}\right)$ ranges respectively. Interestingly, the sawdustbased porous carbons prepared under mild activation conditions $(\mathrm{KOH} / \mathrm{HC}=2)$ exhibit better $\mathrm{CO}_{2}$ capture capacities than under $\mathrm{KOH} / \mathrm{HC}=4$ (see Table 2). The $\mathrm{CO}_{2}$ adsorption isotherms of the carbon samples prepared under these activation conditions are shown in Figure 5. These adsorption isotherms show that the porous carbons obtained under mild activation conditions $(\mathrm{KOH} / \mathrm{HC}=2)$ have very large $\mathrm{CO}_{2}$ uptakes. Thus, at $0^{\circ} \mathrm{C}$ they are in the 5.8-6.6 mmol $\mathrm{CO}_{2} \cdot \mathrm{g}^{-1}\left(255-288 \mathrm{mg} \mathrm{CO} \cdot \mathrm{g}^{-1}\right)$ range (see Table 2). At $25^{\circ} \mathrm{C}$, the amount of $\mathrm{CO}_{2}$ adsorbed clearly diminishes with the activation temperature, from $4.8 \mathrm{mmol} \mathrm{CO} \cdot \mathrm{g}^{-1}(212 \mathrm{mg}$ $\left.\mathrm{CO}_{2} \cdot \mathrm{g}^{-1}\right)$ at $600^{\circ} \mathrm{C}$ to $3.9 \mathrm{mmol} \mathrm{CO}_{2} \cdot \mathrm{g}^{-1}\left(170 \mathrm{mg} \mathrm{CO} 2 \cdot \mathrm{g}^{-1}\right)$ at $800^{\circ} \mathrm{C}$. As expected for an exothermic process such as $\mathrm{CO}_{2}$ physisorption, the amount adsorbed decreases with the 
increase in adsorption temperature. The isosteric heat of adsorption was calculated by applying the Clausius-Clapeyron equation to the adsorption isotherms (adsorption uptake $\left.0.7 \mathrm{mmol} \mathrm{CO} 2 \cdot \mathrm{g}^{-1}\right)$. The values found for the enthalpy of adsorption of these samples are $20 \pm 2 \mathrm{~kJ} \cdot \mathrm{mol}^{-1}$, which is consistent with the data reported for $\mathrm{CO}_{2}$ adsorption on porous carbons. $^{25}$

It should be pointed out that, whereas the porous carbons prepared at $\mathrm{KOH} / \mathrm{HC}=2$ have a considerably poorer pore development than those obtained at $\mathrm{KOH} / \mathrm{HC}=4$ (see Table 1), they exhibit significantly better $\mathrm{CO}_{2}$ capture capacities (see Table 2). This observation is in agreement with the results shown in Figure 4. A comparison of the pore size distributions of both activated carbon series reveals important differences (see Figure 3 and Table 1). Indeed, as mentioned above, whereas the porosity of the carbons prepared at $\mathrm{KOH} / \mathrm{HC}=2$ is mostly made up of narrow micropores $(<1 \mathrm{~nm}$ ) (see Figure $3 \mathrm{~d})$, the $\mathrm{KOH} / \mathrm{HC}=4$ samples contain quite a large fraction of wide micropores $>1 \mathrm{~nm}$ and mesopores $>2 \mathrm{~nm}$ (see Figure $3 b$ ). These results clearly indicate that the amount of $\mathrm{CO}_{2}$ adsorbed depends heavily on the pore size distribution of the samples. More specifically, they show that the narrow micropores $(<1 \mathrm{~nm})$ have a greater contribution to $\mathrm{CO}_{2}$ adsorption than wide micropores and mesopores. This is due to the fact that these narrow micropores have strong adsorption potentials that enhance their filling by the $\mathrm{CO}_{2}$ molecules. This result show that the fabrication of efficient $\mathrm{CO}_{2}$ carbon sorbents requires a precise control of the porosity, which should be made up by micropores $<1 \mathrm{~nm}$.

It is also worth mentioning that the $\mathrm{CO}_{2}$ capture capacities of the porous carbon samples reported here, and in particular those obtained for the materials prepared under mild activation conditions $(\mathrm{KOH} / \mathrm{HC}=2)$, are among the highest ever reported for porous carbons. This is evidenced by comparing our $\mathrm{CO}_{2}$ uptake data $\left(25^{\circ} \mathrm{C}\right.$ and 1 bar) (see Table 2) with those found in the literature for other porous carbons. The results of the comparison are 
summarized in Table 3. Indeed, to the best of our knowledge, the AS-2-600 sample, prepared under mild activation conditions $\left(\mathrm{KOH} / \mathrm{HC}=2\right.$ and $\left.600^{\circ} \mathrm{C}\right)$, exhibits the highest $\mathrm{CO}_{2}$ uptake value ever measured for a porous carbon at room temperature $\left(25^{\circ} \mathrm{C}\right)$.

\section{Kinetics of adsorption, $\left(\mathrm{CO}_{2} / \mathrm{N}_{2}\right)$ selectivity and sorbent regeneration}

For a low-cost capture of $\mathrm{CO}_{2}$ the selected sorbent must satisfy the following conditions: i) large $\mathrm{CO}_{2}$ uptake, ii) fast adsorption kinetics, iii) good selectivity against other molecules (i. e. $\mathrm{N}_{2}$ ) competing for the adsorption sites and iv) easy regeneration. In the previous section we discussed the capture capacities of the carbon sorbents. Now, the other issues will be addressed. Figure 6 shows the adsorption kinetics of $\mathrm{CO}_{2}$ and $\mathrm{N}_{2}$ over the AS-2-600 carbon sample at $25^{\circ} \mathrm{C}$. These measurements were carried out in a thermogravimetric system, as described in the experimental section. It can be seen that $\mathrm{CO}_{2}$ adsorption is very fast, around $95 \%$ of $\mathrm{CO}_{2}$ uptake occurring in the space of 2 min. By contrast, $\mathrm{N}_{2}$ adsorption is slower, around 60 min being needed for maximum adsorption uptake to take place $\left(0.89 \mathrm{mmol} \mathrm{N}_{2} \cdot \mathrm{g}^{-}\right.$ $\left.{ }^{1}\right)$. This result is interesting because evidences that high $\mathrm{CO}_{2} / \mathrm{N}_{2}$ selectivities can be achieved for short adsorption times. In fact, the $\left[\mathrm{CO}_{2} / \mathrm{N}_{2}\right]$ selectivity measured under equilibrium conditions is 5.4 (see Fig. 6a), but kinetic selectivity measured at an adsorption time of $\sim 2$ min $\left(\sim 95 \%\right.$ of $\mathrm{CO}_{2}$ uptake $)$ is $\sim 9$. This result shows that $\mathrm{CO}_{2}$ and $\mathrm{N}_{2}$ can be effectively separated operating with short adsorption cycle times, which would be highly advantageous for practical applications.

Easy regeneration is another critical property that must be considered when designing $\mathrm{CO}_{2}$ sorbents. In this respect, porous carbons offer certain advantages over other sorbents, such as zeolites. Because of the weak interactions between $\mathrm{CO}_{2}$ and carbon (heat of adsorption $\sim 20 \mathrm{~kJ} \mathrm{~mol}^{-1}$ ) entailing low energy requirements, their regeneration is relatively easy. The regeneration of the carbon sorbents here were tested by means of adsorption $\left(\mathrm{CO}_{2}\right.$ at 1 atm)-desorption (under helium) cycles carried out at room temperature $\left(25^{\circ} \mathrm{C}\right)$. The results 
of the tests for the AS-2-600 sample are illustrated in Figure 6b. It can be seen that the captured $\mathrm{CO}_{2}$ is quickly desorbed after the gas carrier has been switched from $\mathrm{CO}_{2}$ to $\mathrm{He}$. In fact, $>95 \%$ of $\mathrm{CO}_{2}$ is desorbed within $3 \mathrm{~min}$ under these conditions. This adsorptiondesorption cycle was repeated seven times and no noticeable changes were observed in the desorption kinetics or $\mathrm{CO}_{2}$ uptake. In short, the porous carbons reported here can be easily, quickly and totally regenerated over multiple cycles without any loss of adsorption capacity.

\section{Conclusions}

In summary, we have demonstrated that sustainable porous carbons can be easily prepared from hydrothermally-treated polysaccharides (starch and cellulose) or biomass (sawdust) by chemical activation using $\mathrm{KOH}$ as activating agent. The $\mathrm{CO}_{2}$ adsorption properties, kinetics and regeneration of these materials were investigated. The results of our study show that porous carbons prepared using mild activation conditions $(\mathrm{KOH} / \mathrm{HC}=2)$ exhibit very high $\mathrm{CO}_{2}$ adsorption uptakes. Specifically, the sample obtained at an activation temperature of $600^{\circ} \mathrm{C}$ shows an exceptionally high capacity to store $\mathrm{CO}_{2}$ at room temperature (4.8 mmol.g ${ }^{-1}$ at $25^{\circ} \mathrm{C}$ and $\left.1 \mathrm{~atm}\right)$. This remarkable capacity to adsorb $\mathrm{CO}_{2}$ is principally due to the presence of narrow micropores $(<1 \mathrm{~nm})$, with surface area playing a less important role. Furthermore, these porous carbons exhibit a high $\mathrm{CO}_{2}$ adsorption rate, a good selectivity for $\mathrm{CO}_{2}-\mathrm{N}_{2}$ separation and can be easily regenerated.

Acknowledgments. The financial support for this research work provided by the Spanish MCyT (MAT2008-00407) is gratefully acknowledged. M. S. thanks the Spanish MCyT for the award of a Postdoctoral Mobility contract. The authors acknowledge J. L. Baldonedo (UCM) for the TEM images. 


\section{References}

1. A. B. Rao, E. S. Rubin, Env. Sci. Technol., 2002, 36, 4467.

2. D. Aaron, C. Tsouris, Sep. Sci. Technol., 2005, 40, 321.

3. E. S. Kikkinides, R. T. Yang, S. H. Cho, Ind. Eng. Chem. Res., 1993, 32, 2714.

4. K. T. Chue, J. N. Kim, Y. J. Yoo, S. H. Cho, R. T. Yang, Ind. Eng. Chem. Res., 1995, 34, 591.

5. S. Sircar, T. C. Golden, M. B. Rao, Carbon, 1996, 34, 1.

6. B-K. Na, H. Lee, K-K. Koo, H. K. Song, Ind. Eng. Chem. Res., 2002, 41, 5498.

7. D. Ko, R. Siriwardane, L. T. Biegler, Ind. Eng. Chem. Res., 2003, 42, 339.

8. M. T. Ho, G. W. Allinson, D. E. Wiley, Ind. Eng. Chem. Res., 2008, 47, 4883.

9. R. E. Morris, P. S. Wheatley, Angew. Chem. Int. Ed., 2008, 47, 4966.

10. S. Choi, J. H. Drese, C. W. Jones, ChemSusChem, 2009, 2, 796.

11. N. Hedin, L. Chen, A. Laaksonen, Nanoscale, 2010, 2, 1819.

12. X. Xu, C. Song, J. M. Andresen, B. G. Miller, A. W. Scaroni, Energy Fuels, 2002, 16, 1463 .

13. H. Y. Huang, R. T. Yang, D. Chinn, C. L. Munson, Ind. Eng. Chem. Res., 2003, 42, 2427.

14. P. J. E. Harlick, A. Sayari, Ind. Eng. Chem. Res., 2006, 45, 3248.

15. M. B. Yue, Y. C. Y. Cao, X. Dong, J. H. Zhu, Adv. Funct. Mater., 2006, 16, 1717.

16. L. Zhao, Z. Bacsik, N. Hedin, W. Wei, Y. Sun, M. Antonietti, M-M. Titirici, ChemSusChem, 2010, 3, 840.

17. W. R. Alesi, M. Gray, J. R. Kitchin, ChemSusChem, 2010, 3, 948.

18. J. Przepiorski, M. Skrodzewicz, A.W. Morawski, Appl. Surf. Sci., 2004, 225, 235.

19. C. Pevida, T. C. Drage, C. E. Snape, Carbon, 2008, 46, 1464.

20. G-P. Hao, W-C. Li, D. Qian, A-H. Lu, Adv. Mater., 2010, 22, 853.

21. A. Wahby, J. M. Ramos-Fernandez, M. Martinez-Escandell, A. Sepulveda-Escribano, J. Silvestre-Albero, F. Rodriguez-Reinoso, ChemSusChem, 2010, 3, 974.

22. H. Marsh, F. Rodriguez-Reinoso, Activated carbons, Chp. 4, Elsevier, Amsterdam, 2006.

23. M. Sevilla, A. B. Fuertes, Chem. Eur. J., 2009, 15, 4195. 
24. M. Sevilla, A. B. Fuertes, Carbon, 2009, 47, 2281.

25. S. Himeno, T. Komatsu, S. Fujita, J. Chem. Eng. Data 2005, 50, 369.

26. R. V. Siriwardane, M. S. Shen, E. P. Fisher, J. A. Poston, Energy Fuels, 2001, 15, 279.

27. L-Y. Meng, S-J. Park, J. Colloid Interf. Sci., 2010, 352, 498.

28. G. Chandrasekar, W. J. Son and W. S. Ahn, J. Porous Mater., 2009, 16, 545.

29. C. Pevida, M. G. Plaza, B. Arias, H. Fermoso, F. Rubiera, J. J. Pis, Appl. Sur. Sci., 2008, $254,7165$. 
Table 1. Textural properties of activated carbons derived from saccharides and sawdust.

\begin{tabular}{ccccccc}
\hline Sample & $\mathrm{S}_{\text {BET }}\left[\mathrm{m}^{2} \mathrm{~g}^{-1}\right]$ & $\mathrm{S}_{\text {micro }}\left[\mathrm{m}^{2} \mathrm{~g}^{-1}\right]^{\mathrm{a}}$ & $\mathrm{V}_{\mathrm{p}}\left[\mathrm{cm}^{3} \mathrm{~g}^{-1}\right]^{\mathrm{b}}$ & $\mathrm{V}_{\text {micro }}\left[\mathrm{cm}^{3} \mathrm{~g}^{-1}\right]^{\mathrm{a}}$ & $\mathrm{V}_{\mathrm{o}}\left[\mathrm{cm}^{3} \mathrm{~g}^{-1}\right]^{\mathrm{c}}$ & Pore size $[\mathrm{nm}]^{\mathrm{d}}$ \\
\hline AA-4-700 & 2190 & 2080 & 1.01 & 0.92 & 0.35 & 1.2 \\
AC-4-700 & 2370 & 2200 & 1.08 & 0.96 & 0.37 & 1.2 \\
AS-4-600 & 2370 & 2050 & 1.15 & 0.91 & 0.31 & 1.3 \\
AS-4-700 & 2250 & 2090 & 1.03 & 0.91 & 0.35 & 1.2 \\
AS-4-800 & 2850 & 2720 & 1.35 & 1.23 & 0.35 & $1.2 / 2.1$ \\
AS-2-600 & 1260 & 1360 & 0.62 & 0.61 & 0.52 & 0.8 \\
AS-2-650 & 1380 & 1360 & 0.67 & 0.61 & 0.54 & 0.8 \\
AS-2-700 & 1390 & 1360 & 0.69 & 0.62 & 0.60 & 0.9 \\
AS-2-800 & 1940 & 1840 & 0.97 & 0.82 & 0.45 & 0.9 \\
\hline
\end{tabular}

${ }^{\mathrm{a}}$ Evaluated by the t-plot method; ${ }^{\mathrm{b}}$ Total pore volume at $\mathrm{p} / \mathrm{p}_{\mathrm{o}} \sim 0.99 ;{ }^{\mathrm{c}}$ Pore volume of narrow micropores $(<0.7 \mathrm{~nm})$ obtained from the $\mathrm{CO}_{2}$ adsorption data at $0{ }^{\circ} \mathrm{C}$; ${ }^{\mathrm{d}}$ Maxima of the PSDs calculated by NLDFT assuming slit-shaped pores. 
Table 2. $\mathrm{CO}_{2}$ capture capacities of the porous carbons at different adsorption temperatures and $1 \mathrm{~atm}$.

\begin{tabular}{llll}
\hline Sample & \multicolumn{3}{c}{$\mathrm{CO}_{2}$ uptake, $\mathrm{mmol} \cdot \mathrm{g}^{-1}\left(\mathrm{mg} \cdot \mathrm{g}^{-1}\right)$} \\
\cline { 2 - 4 } & $0^{\circ} \mathrm{C}$ & $25^{\circ} \mathrm{C}$ & $50^{\circ} \mathrm{C}$ \\
\hline AA-4-700 & $5.6(247)$ & $3.5(152)$ & $2.2(96)$ \\
AC-4-700 & $5.8(256)$ & $3.5(155)$ & $1.8(79)$ \\
AS-4-600 & $5.2(230)$ & $2.9(128)$ & - \\
AS-4-700 & $5.5(243)$ & $2.9(128)$ & $1.8(79)$ \\
AS-4-800 & $5.2(227)$ & $3.0(130)$ & - \\
AS-2-600 & $6.1(270)$ & $4.8(212)$ & $3.6(158)$ \\
AS-2-650 & $6.0(262)$ & $4.7(206)$ & $3.3(145)$ \\
AS-2-700 & $6.6(288)$ & $4.3(190)$ & $2.6(116)$ \\
AS-2-800 & $5.8(255)$ & $3.9(170)$ & $3.1(136)$ \\
\hline
\end{tabular}


Table 3. Comparison of $\mathrm{CO}_{2}$ uptakes $\left(25^{\circ} \mathrm{C}\right.$ and $\left.1 \mathrm{~atm}\right)$ for different porous carbon sorbents.

\begin{tabular}{lll}
\hline Sorbent & $\begin{array}{l}\mathrm{CO}_{2} \text { uptake } \\
\mathrm{mmol} \mathrm{g}^{-1}\left(\mathrm{mg} \mathrm{g}^{-1}\right)\end{array}$ & Reference \\
\hline Commercial activated carbon (BPL) & $2.1(92)$ & 3 \\
Commercial activated carbon (G-32 H) & $2.5(110)$ & 26 \\
Ammonia treated activated carbon (C35N400) & $1.7(76)$ & 18 \\
Activated graphite fibres (G-900) & $1.3(59)$ & 27 \\
Mesoporous carbon (CMK-3) & $1.7(76)$ & 28 \\
N-doped activated carbon (MFB-600) & $2.3(101)$ & 19 \\
Ammonia treated activated carbon (RN800) & $2.2(96)$ & 29 \\
N-doped porous carbon (RFL-500) & $3.1(136)$ & 20 \\
Activated carbon from petroleum pitch (DO-88-M) & $4.7(207)$ & 21 \\
Sawdust-based porous carbon (AS-2-600) & $4.8(212)$ & This work \\
\hline
\end{tabular}




\section{Figure Captions}

Figure 1. SEM images of (a) eucalyptus sawdust, (b) HC-starch, (c) HC-cellulose, (d) HCsawdust and (e) AS-4-800 activated carbon, and TEM image of the AS-4-700 sample (f).

Figure 2. $\mathrm{N}_{2}$ sorption isotherms and pore size distributions (insets) for the activated carbons prepared from hydrochar samples derived from starch, cellulose and sawdust.

Figure 3. $\mathrm{N}_{2}$ sorption isotherms (a, c) and pore size distributions (b, d) of activated carbons prepared from $\mathrm{HC}$-sawdust at different activation temperatures and $(\mathrm{KOH} / \mathrm{HC})$ weight ratios of 4 (Fig. a and Fig. b) and 2 (Fig. c and Fig. d).

Figure 4. Comparison of $\mathrm{CO}_{2}$ adsorption isotherms at $25^{\circ} \mathrm{C}$ for hydrochar-based porous carbons and a commercial activated carbon (M-30).

Figure 5. $\mathrm{CO}_{2}$ adsorption isotherms at $0^{\circ} \mathrm{C}(\circ), 25^{\circ} \mathrm{C}(\square)$ and $50^{\circ} \mathrm{C}(\Delta)$ for the porous carbons obtained when $\mathrm{KOH} / \mathrm{HC}=2$ at the following activation temperatures: (a) $600^{\circ} \mathrm{C}$ (AS-2-600), (b) $650^{\circ} \mathrm{C}$ (AS-2-650), (c) $700^{\circ} \mathrm{C}$ (AS-2-700) and (d) $800^{\circ} \mathrm{C}$ (AS-2-800).

Figure 6. (a) Adsorption kinetics of $\mathrm{CO}_{2}$ and $\mathrm{N}_{2}$ at $25^{\circ} \mathrm{C}$ for the AS-2-600 sample and (b) $\mathrm{CO}_{2}$ Adsorption-desorption cycles obtained for the AS-2-600 sample at $25^{\circ} \mathrm{C}\left(\mathrm{CO}_{2}\right.$ concentration: $100 \%)$. 

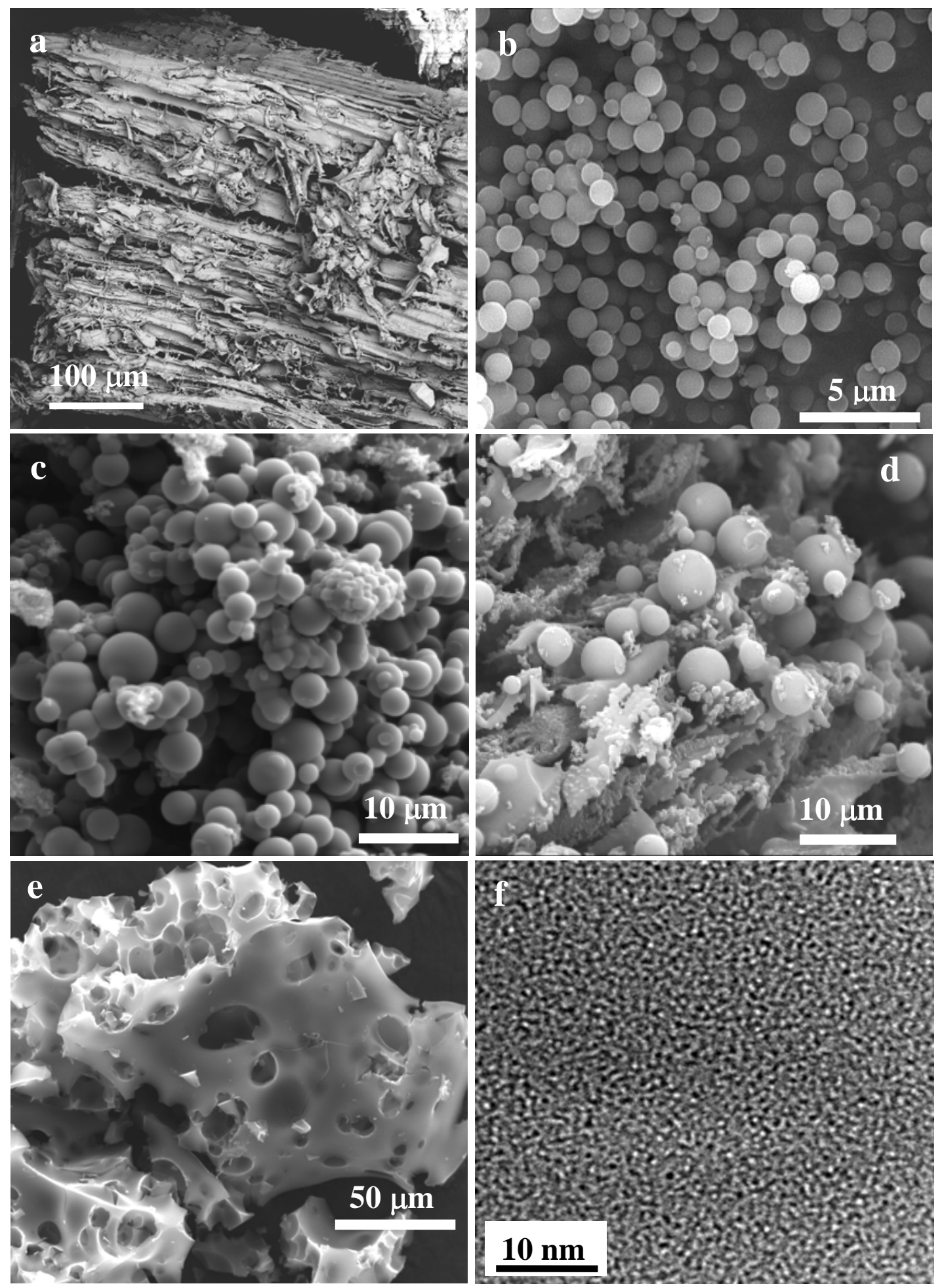

$10 \mathrm{~nm} 554 \%$ in

Figure 1 


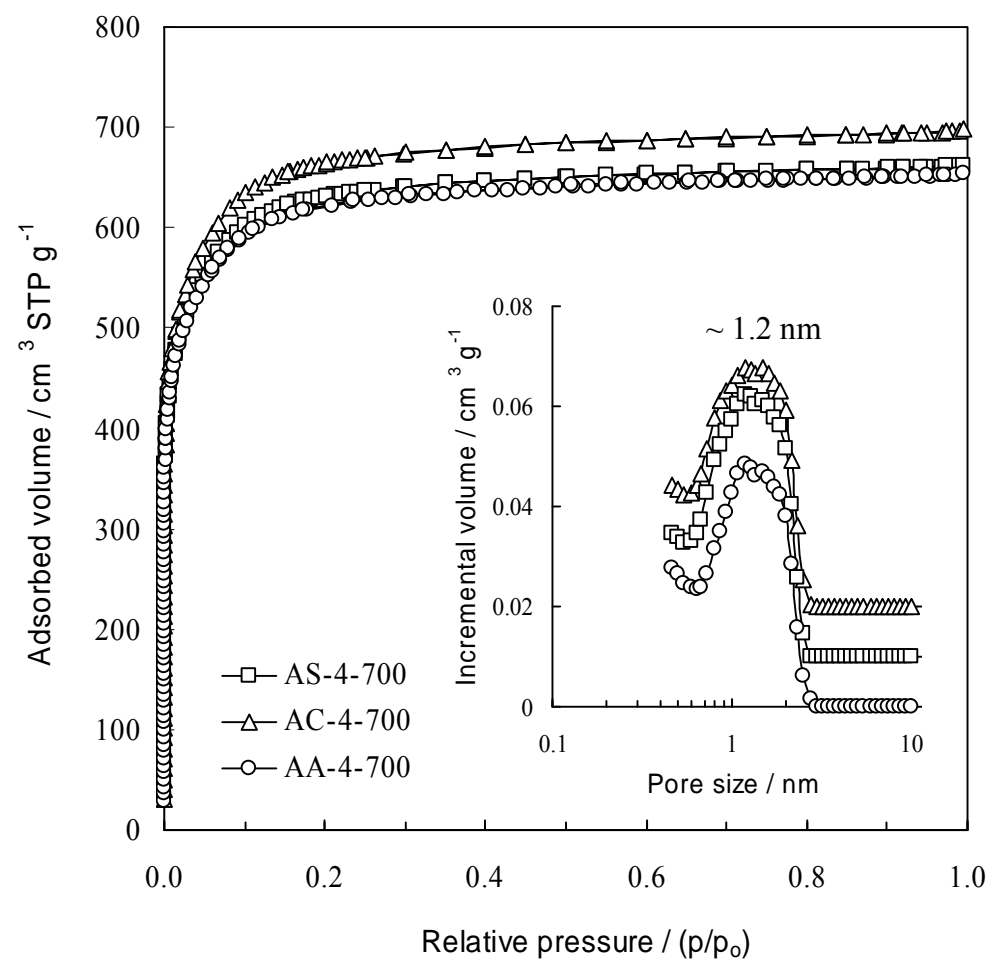

Figure 2 

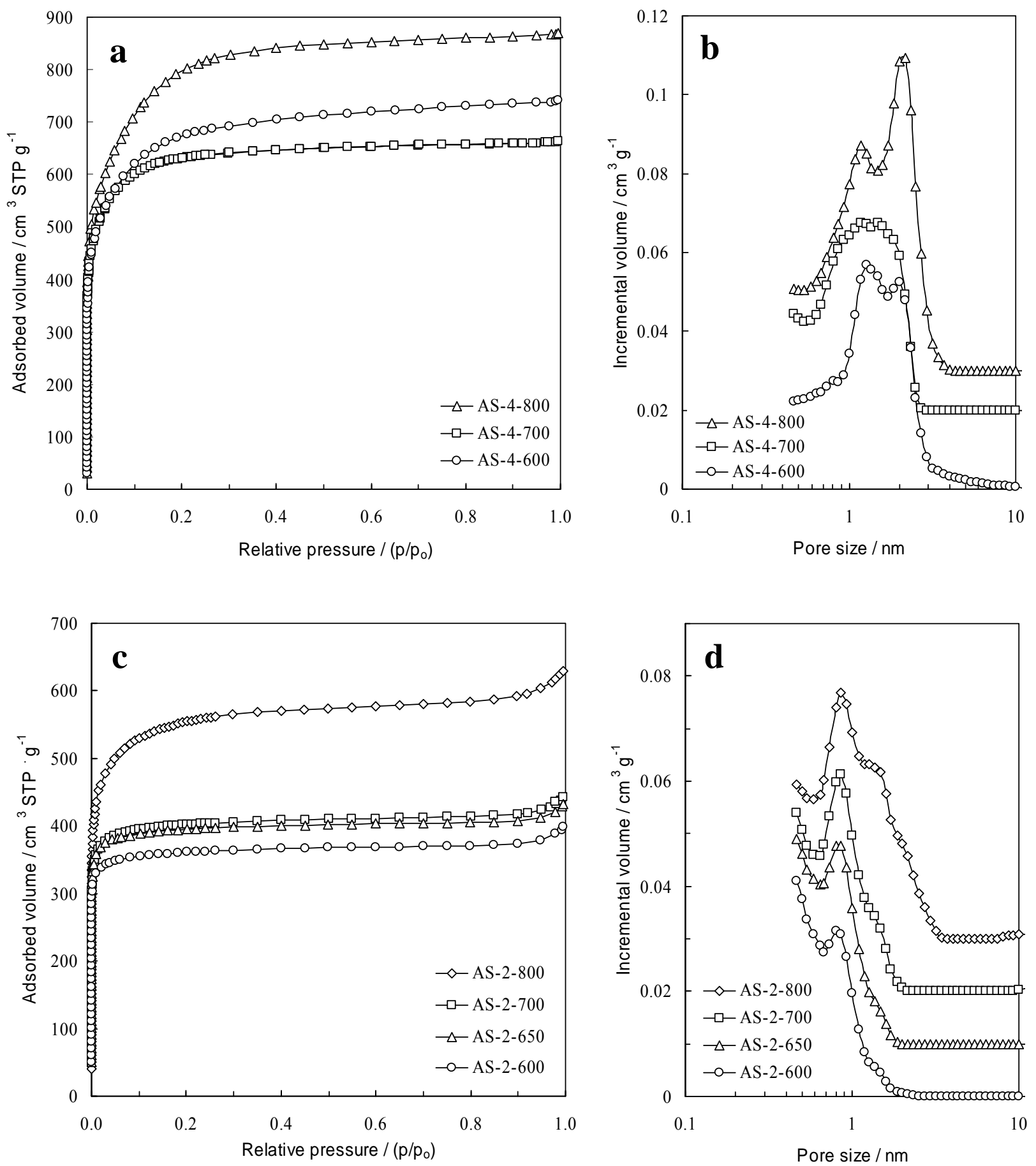

Figure 3 


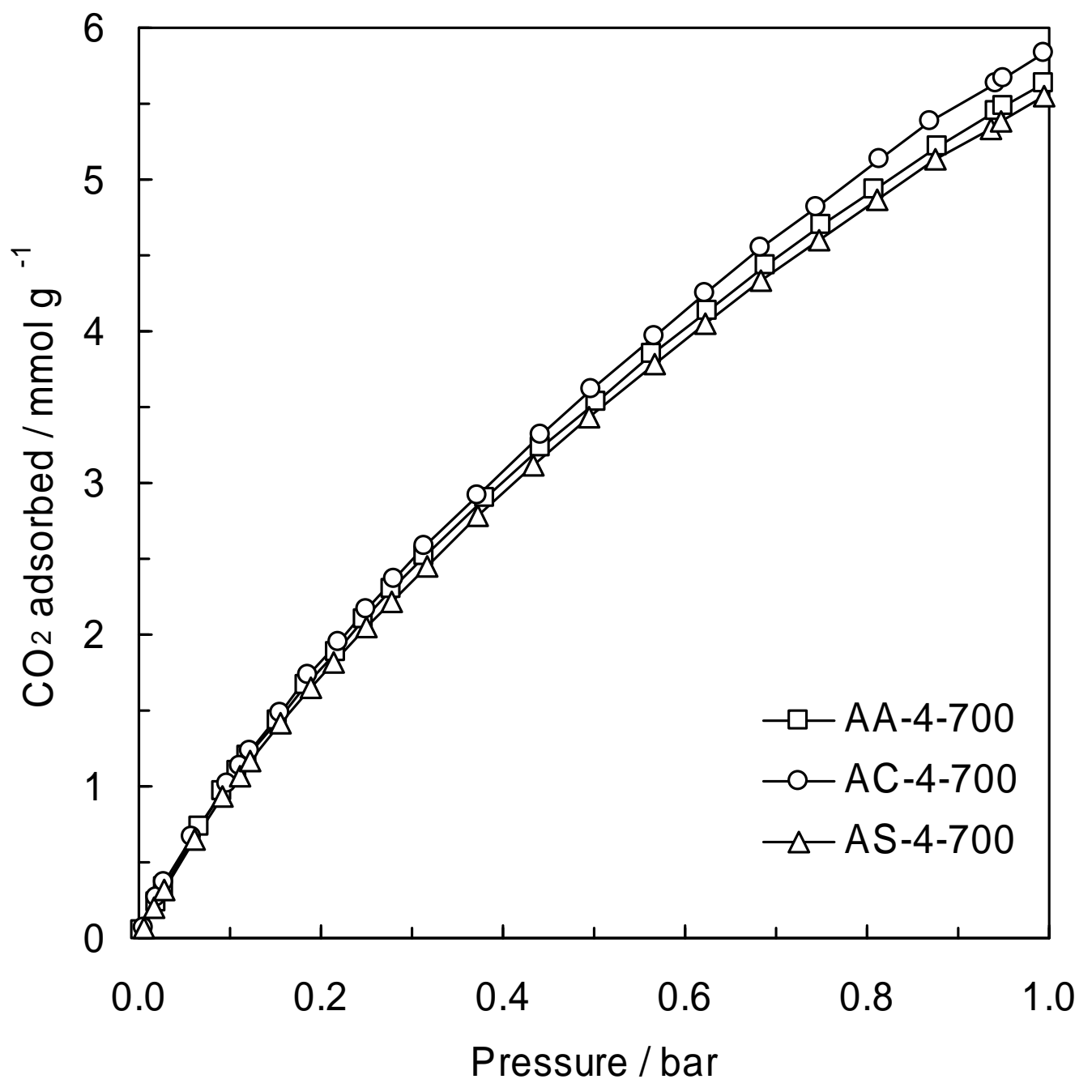

Figure 4 

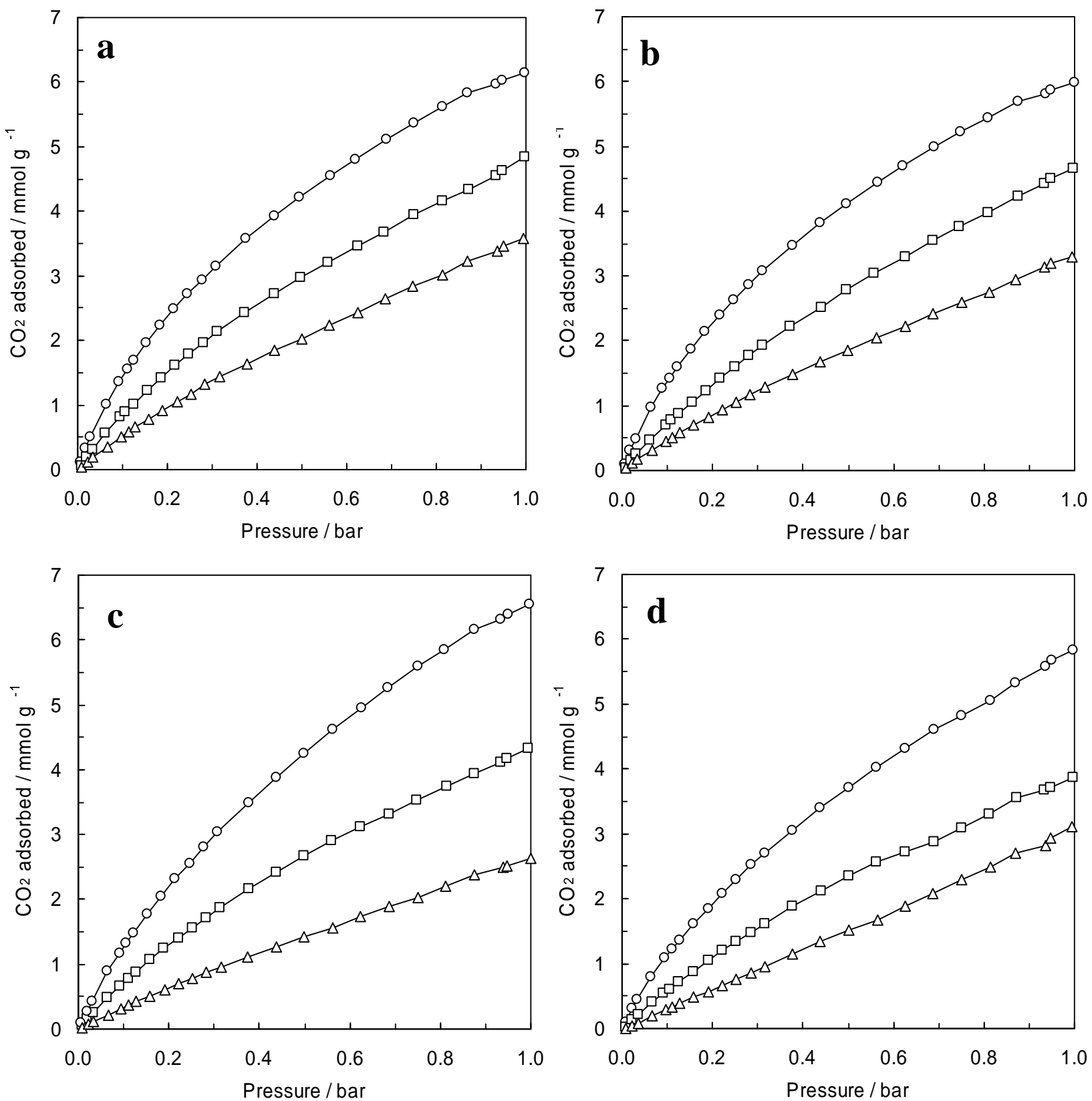

Figure 5 

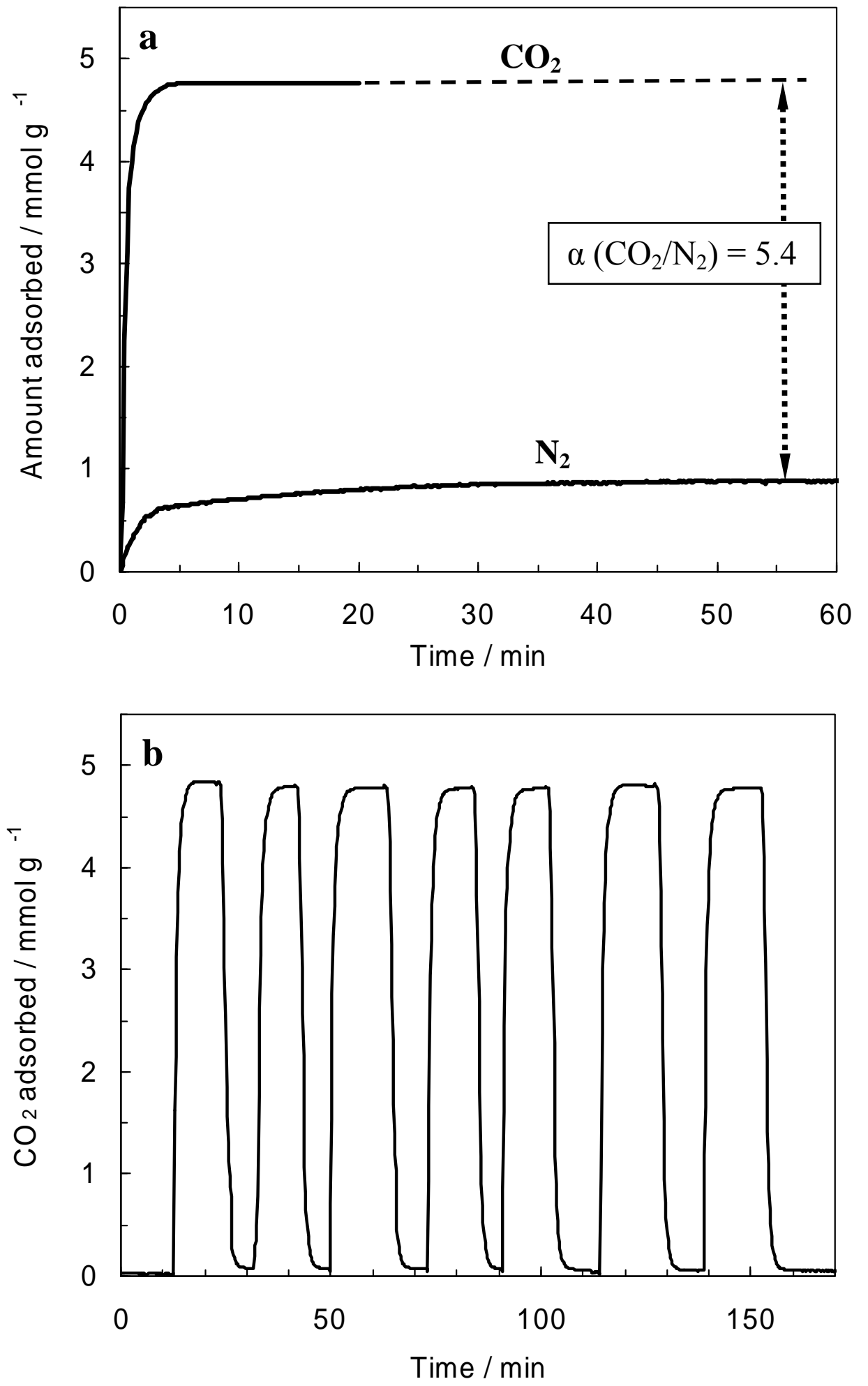

Figure 6 


\section{Graphical Abstract}

The preparation and characterization of carbon-based $\mathrm{CO}_{2}$ porous sorbents obtained from a low-cost sustainable biomass product (sawdust) is presented. These sorbents exhibit high $\mathrm{CO}_{2}$ uptakes, fast sorption kinetics and easy regenerability.

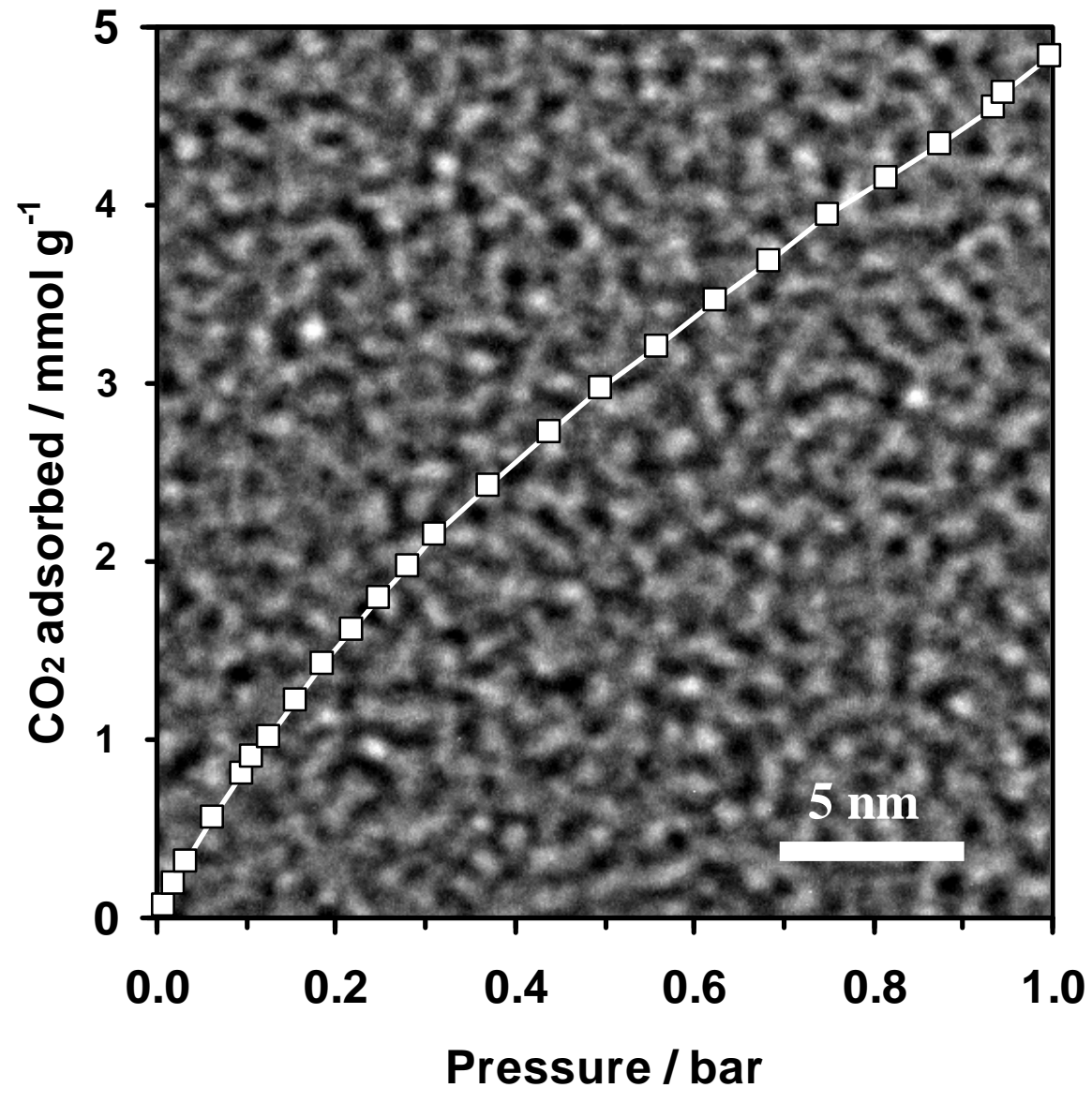

